Table 1. Baseline predictors of reduction of disease activity at $\mathbf{1 2}$ months from start of abatacept. Linear regression

\begin{tabular}{|c|c|c|c|c|c|c|c|c|c|}
\hline \multirow[b]{2}{*}{ Variables } & \multicolumn{3}{|c|}{ Bivariate } & \multicolumn{3}{|c|}{ Adjusted for baseline DAS28 } & \multicolumn{3}{|c|}{ Multivariate } \\
\hline & $\mathrm{B}$ & $95 \% \mathrm{Cl}$ & $P$-value & $\mathrm{B}$ & $95 \% \mathrm{Cl}$ & $P$-value & $\mathrm{B}$ & $95 \% \mathrm{Cl}$ & $P$-value \\
\hline Male sex & 0.39 & {$[0.13,0.64]$} & 0.003 & 0.43 & {$[0.20,0.66]$} & $<0.001$ & 0.42 & {$[0.19,0.64]$} & $<0.001$ \\
\hline Age (per SD) & 0.10 & {$[-0.004,0.21]$} & 0.058 & 0.044 & {$[-0.051,0.14]$} & 0.37 & & N/A & \\
\hline RA duration (per SD) & -0.14 & {$[-0.25,-0.037]$} & 0.008 & -0.11 & {$[-0.21,-0.016]$} & 0.022 & -0.030 & {$[-0.13,0.065]$} & 0.54 \\
\hline $\mathrm{HAQ}$ (per SD) & 0.12 & {$[0.007,0.23]$} & 0.037 & -0.24 & {$[-0.35,-0.13]$} & $<0.001$ & & N/A & \\
\hline VAS pain (per SD) & 0.26 & {$[0.15,0.37]$} & $<0.001$ & -0.058 & {$[-0.17,0.054]$} & 0.31 & & & \\
\hline MTX $^{1}$ & 0.20 & {$[-0.013,0.41]$} & 0.066 & 0.17 & {$[-0.018,0.36]$} & 0.076 & 0.11 & {$[-0.076,0.29]$} & 0.25 \\
\hline Prednisolone $^{1}$ & -0.19 & {$[-0.41,0.017]$} & 0.072 & -0.17 & {$[-0.36,0.024]$} & 0.087 & -0.14 & {$[-0.33,0.043]$} & 0.13 \\
\hline bDMARDs ${ }^{2}$ (per SD) & -0.30 & {$[-0.40,-0.20]$} & $<0.001$ & -0.32 & {$[-0.41,-0.23]$} & $<0.001$ & -0.31 & {$[-0.40,-0.21]$} & $<0.001$ \\
\hline
\end{tabular}

$\mathrm{B}=$ beta coefficient; $\mathrm{N} / \mathrm{A}=$ not applicable; $\mathrm{SD}=$ standard deviation; $\mathrm{Cl}=$ confidence interval. Bold text indicates significant associations.DAS28, Disease activity Score of 28 joints; RA, rheumatoid arthritis; HAQ, Health Assessment Questionnaire; VAS, visual analogue scale; MTX, methotrexate; bDMARD, biologic disease-modifying antirheumatic drug. ${ }^{1}$ Current treatment ${ }^{2}$ Number of previous bDMARDs

Disclosure of Interests: Julia Liukkonen: None declared, Giovanni Cagnotto: None declared, Jan-Åke Nilsson: None declared, Saedis Saevarsdottir: None declared, Carl Turesson Speakers bureau: Abbvie, Bristol Myers-Squibb, Medac, Pfizer, Roche., Consultant of: Roche, Grant/research support from: This study was supported by an unrestricted grant from Bristol-Myers Squibb DOI: 10.1136/annrheumdis-2021-eular.2867

\section{POS0630 \\ COMPARISON OF THE EFFICACY AND SAFETY OF ORIGINAL AND BIOSIMILAR ADALIMUMAB MOLECULES IN CHILDHOOD RHEUMATIC DISEASES}

K. Ulu ${ }^{1}$, F. Demir ${ }^{1}$, T. Coşkuner ${ }^{1}$, Ş. Çağlayan ${ }^{1}$, B. Sözeri ${ }^{2} .{ }^{1}$ Umraniye Training and Research Hospital, Pediatric Rheumatology, Istabul, Turkey; ${ }^{2}$ Umraniye Training and Research Hospital, Pediatric Rheumatology, Istabul, Turkey

Background: The TNF- $\alpha$ inhibitor adalimumab is a biological disease modifying anti-rheumatic drug (bDMARD) that has been used in different rheumatic diseases with a resistant course. ABP-501 is a biosimilar product (BP) of adalimumab, recently approved by the FDA and EMA. To our knowledge, there is no study assess the efficacy and safety of these two molecules on pediatric patients.

Objectives: We aimed to compare the efficacy and safety of the original and biosimilar adalimumab (ABP-501) molecules in childhood rheumatic diseases.

Methods: This non-interventional, retrospective, single-centre analysis carried out in Umraniye Training and Resrach Hospital, Pediatric Rheumatology Clinic, Istanbul, Turkey. The study group consisted of patients who were followed due to chronic rheumatic disease between January 1, 2016 and June 1,2020, and received reference or biosimilar adalimumab therapy for at least three months. Demographic and clinical data of patients were collected at baseline, $3^{\text {rd }}, 6^{\text {th }}$, and $12^{\text {th }}$ months of treatment. Disease activity assessment was made with JADAS-27 in JIA patients, with SUN criteria in uveitis patients, and with Behçet's Disease Activity Index in BD patients. Efficacy and safety of treatments were compared between reference and biosimilar adalimumab groups.

Results: A total of 89 patients ( 65 with original and 24 with biosimilar molecule) treated with adalimumab, were included in the study. There were 45 female and 44 male in the study, and the median age at the initiation of the adalimumab was 166 months (min-max: 36-231). Of the 89 patients evaluated, the primary diagnoses of 62 were juvenile idiopathic arthritis, 13 were idiopathic uveitis, eight were Behçet's disease, three were Blau syndrome, two were chronic recurrent multifocal osteomyelitis and one was Vogt-Koyanagi-Harada syndrome. 63 of the patients were biologic-naïve, and 13 were switched from etanercept, 11 from infliximab, and two from other bDMARDs. The median exposure time of adalimumab was 16 months (min-max:3-70) in RP and 14.5 months (min-max: 3-23) in BP. All patients had active disease before treatment. In the group treated with $\mathrm{RP}$, inactive disease was achieved in $60 \%, 76.6 \%$ and $87.2 \%$ of the patients at the $3 \mathrm{rd}, 6$ th and 12th months, respectively. Also, inactive disease was achieved in $62.5 \%, 78.2 \%$ and $78.2 \%$ of the patients at the 3rd, 6 th and 12 th month in the group treated with BP, respectively. There was no statistically significant difference in efficacy between the groups at the 3rd, 6th and 12th months $(p=0.83$, 0.07 and 0.32). Serious adverse events were seen in one patient in each groups (lymphoma in RP group, tuberculous meningitis in BP group). Non-serious adverse events were observed in eight patients (12.3\%) in the RP group and in two patients (8.3\%) in the BP group, without statistically significant difference between groups $(p=0.86)$.

Conclusion: No significant difference was observed between the biosimilar adalimumab ABP-501 and RP adalimumab in terms of efficacy and safety.

REFERENCES :

[1] Renton, William D et al. Pediatr Rheumatol Online J. 2019;17(1):67.

[2] Lovell DJ, Ruperto N, Goodman S, et al. N Engl J Med.2008;359(8):810-820.

[3] Kingsbury, Daniel J et al. Clin Rheumatol 2014;33(10):1433-41.

Disclosure of Interests: None declared

DOI: 10.1136/annrheumdis-2021-eular.2979

\section{POS0631 COMPARATIVE EFFICACY OF COMBINATION THERAPY WITH BIOLOGIC OR TARGET SYNTHETIC DRUGS FOR RHEUMATOID ARTHRITIS: A BAYESIAN NETWORK META-ANALYSIS}

F. Cacciapaglia ${ }^{1}$, V. Venerito ${ }^{1}$, S. Stano ${ }^{2}$, M. Fornaro ${ }^{1}$, G. Lopalco ${ }^{1}$, F. Iannone ${ }^{1}$. ${ }^{1}$ University and AOUC Policlinico of Bari, Department of Emergency and Organs Transplantation, Bari, Italy; ${ }^{2}$ School of Medicine University of Bari, Department of Emergency and Organs Transplantation, Bari, Italy

Background: Biologic agents and small molecules have shown long term benefit when added in patients with active RA non-responders to conventional DMARDs treatment (1). In head-to-head trials only adalimumab was compared to other drugs in combination with methotrexate, with some evidence of superiority but no data on multiple comparisons have been reported (2). The availability of biosimilar agents led in clinical practice to prefer mainly the cheaper one, so the choice of the most effective treatment remains a clinical unmet need (3).

Objectives: To assess the relative efficacy of different therapeutic strategies for achieving ACR50 response at 24 weeks of treatment in patients with active RA, based on direct and indirect evidence.

Methods: We performed systematic reviews of MEDLINE, EMBASE, and Cochrane Library databases, searching for all published phase 3 Randomised Controlled Trials (RCTs) comparing adalimumab originator to its biosimilars, abatacept, baricitinib, certolizumab pegol, tofacitinib or upadacitinib, combined to MTX, in patients with active RA inadequate responders to previous conventional DMARDs. American College of Rheumatology (ACR) 50\% response at 24 weeks of treatment had to be evaluated both in adalimumab branch and in examined drug branch. Bayesian fixed-effect network meta-analysis was performed to combine the direct and indirect evidence using the WinBUGS 1.4 software (MRC Biostatistics Unit, Cambridge, UK).

Results: Eleven RCTs evaluating 6'004 patients were included in the analysis, namely originator (1) and biosimilars (2) adalimumab, abatacept (3), baricitinib (4), certolizumab pegol (5), tofacitinib (6) and upadacitinib (7). Convergence was reached at n.100'000 iterations. Upadacitinib seems to be more effective than both originator and biosimilar adalimumab in achieving ACR 50 (OR $1.6595 \% \mathrm{Cl} 1.25-2.14$ and OR 1.22 95\%Cl 1.102.18; see Figure 1). Similarly, tofacitinib was more effective of originator adalimumab (OR 1.25 95\% Cl 1.01-155). Upadacitinib was ranked first among treatments with a probability of being the agent more likely to induce ACR 50 response of $86.3 \%$. In this regard tofacitinib had a probability of $4.8 \%$, hence it was ranked second among treatments.

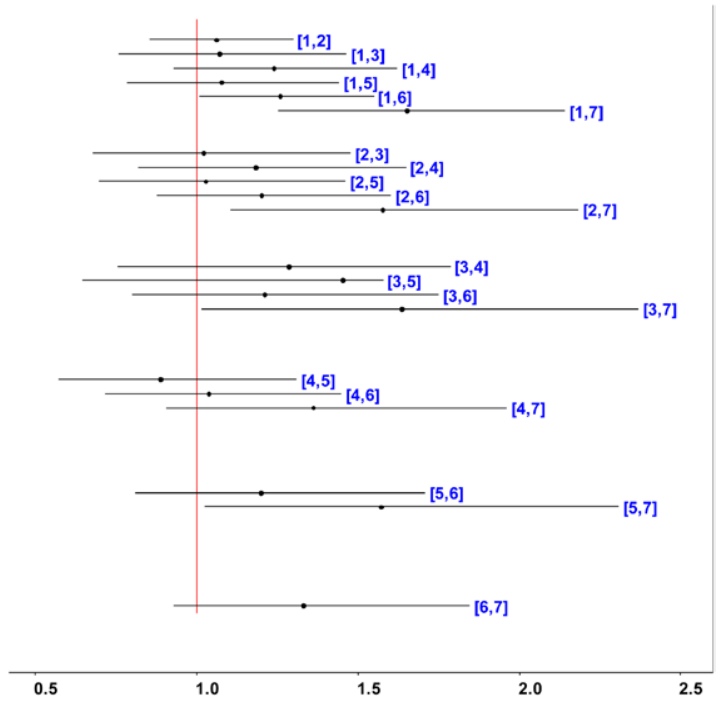

Figure 1. Caterpillar plot OR for ACR50 at 24 weeks (originator [1] and biosimilars [2] adalimumab; abatacept [3]; baricitinib [4]; certolizumab pegol [5]; tofacitinib [6]; upadacitinib [7]). 